Article

\title{
Evaluating the Interests of Different Stakeholders in Beijing Wastewater Reuse Systems for Sustainable Urban Water Management
}

\author{
Xiao Liang ${ }^{1, *}$ and Meine Pieter van Dijk ${ }^{2}$ \\ 1 School of Economics, Shenzhen University, Shenzhen 518060, Guangdong, China \\ 2 International Institute of Social Studies, The Hague 2518 AX, The Netherlands; mpvandijk@iss.nl \\ * Correspondence: x.liang@yahoo.com; Tel.: +86-755-2673-3256 \\ Academic Editor: Marc A. Rosen \\ Received: 13 September 2016; Accepted: 22 October 2016; Published: 27 October 2016
}

\begin{abstract}
Whether water systems can be operated successfully and sustainably is influenced by the attitudes and willingness of stakeholders involved in the management of such systems. This study quantitatively evaluates the interests of different stakeholders in wastewater reuse systems in Beijing. Such interests comprise economic, environmental, and social effects induced by the wastewater reuse systems. The study considers four main stakeholders in Beijing, namely the Municipal Administration Committee (MAC), Municipal Environmental Protection Bureau (MEPB), plant managers, and users. Cost benefit analysis is conducted to determine the aforementioned interests separately from the perspectives of the various stakeholders. The results reveal that not all stakeholders' interests in the wastewater reuse systems in Beijing are satisfied. From the perspectives of both the MAC and $\mathrm{MEPB}$, the evaluation results indicate that both decentralized and centralized wastewater reuse systems are economically feasible. However, from the viewpoints of plant managers and users, the results reveal that only the centralized wastewater reuse systems are economically feasible, whereas the decentralized systems are not. The failure to satisfy the interests of plant managers and users may be a major reason for the interrupted operation of the decentralized systems in Beijing. The study demonstrates that successful and sustainable development of a new water project necessitates satisfying the interests of all stakeholders.
\end{abstract}

Keywords: wastewater reuse; stakeholders; cost benefit analysis; water management

\section{Introduction}

Whether water systems can be operated successfully and sustainably is predominantly influenced by the attitudes and willingness of stakeholders involved in the management of such systems [1]. Different stakeholders may have different concerns on a water system [2,3]. For example, plant managers pay more attention to the profitability of water systems, users place more emphasis on living costs saving and convenience, and the government attaches greater importance on the influence of the water scheme on society. The opinions of different stakeholders could lead to different attitudes and willingness toward water management matters, and then significantly affect a smooth and successful operation of water systems $[4,5]$.

In Beijing, wastewater reuse has been extensively promoted since the $1980 \mathrm{~s}$, but the emphasis is centered on decentralized systems. Decentralized wastewater reuse entails reclaiming and reusing wastewater on site; this procedure involves a small treatment scale. Decentralized wastewater reuse has been successfully implemented in Japan, Australia, and certain European countries [6,7]. Moreover, relevant policies on constructing decentralized wastewater reuse systems have been issued gradually in Beijing. For example, in 1987, the government issued "The draft regulation on building decentralized 
wastewater reuse systems in Beijing," which required that all institutes including hotels, schools, and residences with areas exceeding $30,000 \mathrm{~m}^{2}$ construct decentralized wastewater reuse plants. In 2002, "A comprehensive regulation on the management of wastewater reuse systems" was implemented with more details rules. Since 2000, centralized wastewater reuse systems have been promoted and constructed. Centralized water reuse involves treating wastewater in a large plant centrally and then distributing the treated water to users. Compared with decentralized systems, centralized systems are traditional modes that treat water centrally and on large scales. Currently, Beijing comprises thousands of decentralized wastewater reuse plants and five centralized plants.

The total amount of reused wastewater is increasing gradually, as illustrated in Figure 1. Except for decentralized wastewater reuse systems established for industrial use, most of the decentralized systems in Beijing do not operate as expected. Parts of the decentralized systems operate irregularly; parts of decentralized systems were no longer functioning. Moreover, the establishment of centralized systems is increasing slowly despite the government extensively promoting wastewater reuse $[8,9]$.

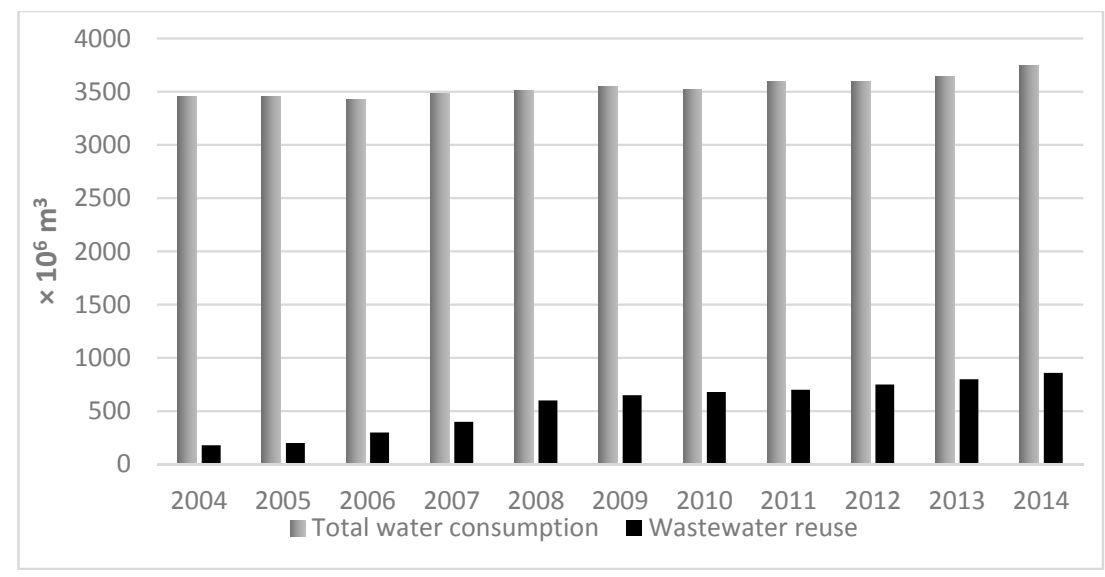

Figure 1. Change in total water consumption and amount of reused wastewater. (Sourced from Beijing Water Resources Bulletin).

The Municipal Administration Committee (MAC), Municipal Environmental Protection Bureau (MEPB), plant managers, and users are the main stakeholders of wastewater reuse systems in Beijing, and their interests in such plants may differ. The MAC promotes and subsidizes the construction of wastewater reuse plants; managers oversee the daily operation of the plants; the MEPB inspects such plants; users have rights to decide whether to use the reused water or not. Although numerous studies have examined wastewater reuse systems from technological perspectives, such viewpoints determine only the physical operation of the plants without reflecting management issues [10,11]. The current study determines whether each stakeholder's interests in wastewater reuse are satisfied or not during operation.

Estimations of the interests of different stakeholders can effectively explain the diverse situations between the centralized and decentralized wastewater reuse systems in Beijing. In the reviewed literature, certain studies have discussed different stakeholders' perceptions and interests toward water management. Chen et al. showed the perceptions of different stakeholders on water reuse [2]. Sa-nguanduan and Nititvattananon's study presented the environmental, economic, social, and technical interests of different stakeholders on water reuse [3]. These studies have qualitatively represented the opinions of different stakeholders, revealing a concept map to decision makers. The interests of different stakeholders have been rarely estimated quantitatively. Quantitative analysis of the interests of different stakeholders benefits further comparative research and hence obtains an all-inclusive and profound conclusion.

The study quantitatively estimates the interests of the main stakeholders of wastewater reuse systems in Beijing. Such interests include the economic, environmental, and social effects engendered 
by wastewater reuse, which are evaluated separately from the perspectives of different stakeholders. About the method on evaluating the sustainability of recycled water schemes, Chen et al. have reviewed several tools, including Life Cycle Assessment (LCA), Material Flow Analysis (MFA) and Environmental Risk Assessment (ERA) in terms of their types, characteristics and weaknesses [12]. In this study, the method of Cost Benefit Analysis (CBA) is applied. CBA could facilitates effectively the estimation of the effects of wastewater reuse, a comparative analysis among stakeholders, and comparison between centralized and decentralized systems [13]. Moreover, besides CBA, Multi-Criteria Analysis (MCA) is conducted in various sectors for assessing the decision making process, such as solid waste management systems [14], energy [15], sustainability assessment of tertiary wastewater treatment technologies [16], etc.

The current study is based on two previous studies: the study by Liang and Van Dijk (2010), who conducted an economic analysis of Beijing's decentralized wastewater reuse plants, and that by Liang and van Dijk (2012), who conducted an economic evaluation of Beijing's centralized wastewater reuse plants $[9,17]$. In the current study, some parts of the evaluation and data are sourced from these two studies; nevertheless, this study re-estimates the data and constructs a new analysis, which is an advancement of these two previous ones. All data in the study are collected through the interviews with different stakeholders.

\section{Studied Wastewater Reuse Systems}

Four wastewater reuse plants are chosen for the study: Two of the plants are decentralized (denoted as Plants 1 and 2), and the remaining are centralized (denoted as Plants 3 and 4). As shown in Figure 2, the centralized plants are located in the suburban area, whereas the decentralized plants are located in the city center. Different locations of wastewater reuse plants may incur different effects.

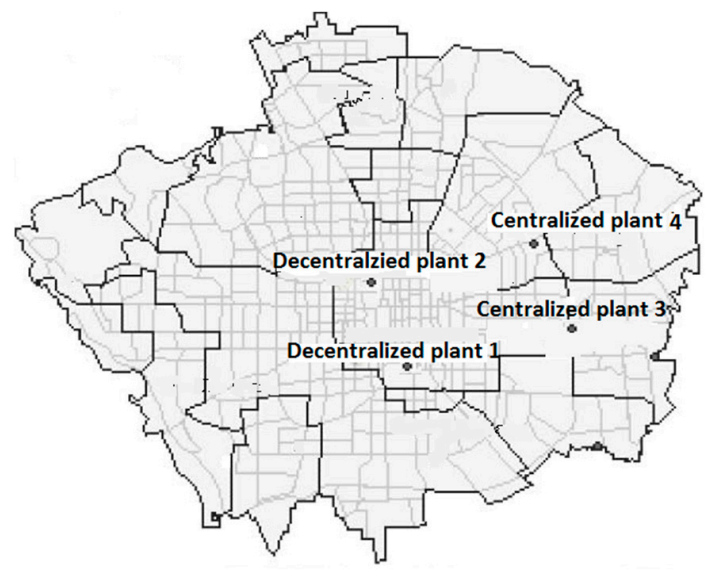

Figure 2. Location of Beijing centralized and decentralized wastewater reuse plants studied.

A decentralized wastewater reuse system is usually built for a single construction site or institute, collecting greywater from the construction site directly and then processing it on site. Plant 1 , with a daily production capacity of $65 \mathrm{~m}^{3}$, is located in a residential area and serves approximately 2500 people. Its reused water is mainly for toilet flushing and green area irrigation. The plant is constructed underground beside a residential parking area; its depth is $8 \mathrm{~m}$, and its area is $218 \mathrm{~m}^{2}$. Plant 2, with a daily production capacity of $400 \mathrm{~m}^{3}$, is built on a university campus, serving approximately 30,000 people. This plant collects water from the public shower lounge, and then the reclaimed water is used for toilet flushing in student accommodations and green land irrigation.

A centralized wastewater reuse system is generally established at a large scale, reclaiming wastewater and then distributing the reused water for multiple functions. Plant 3 is the largest and first centralized wastewater reuse plant in Beijing, and it has been in operation since 2000. The daily capacity of plant 3 is approximately $470,000 \mathrm{~m}^{3}$, of which $40 \%$ is discharged to "The First Electricity 
Factory" for cooling, $4 \%$ is delivered to "The Sixth Water Factory" for reprocessing for industrial use, and the remaining is distributed for residential use, greening and agricultural irrigation. Plant 4 was constructed in 2004, and it processes $60,000 \mathrm{~m}^{3}$ of reused water daily, of which $30 \%$ is for residential use, $50 \%$ is for lake or river water supplementation, $10 \%$ is for green land irrigation, and the remaining $10 \%$ is for agricultural irrigation.

\section{Evaluation Method}

As shown in Figure 3, this study separately evaluates the effects of wastewater reuse systems from the perspectives of the MAC, the MEPB, plant managers and users. For centralized wastewater reuse systems in Beijing, the drainage group is mainly in charge of the daily operations and maintenance of the plants. The MAC, representing the government, promotes and subsidizes the construction and operation of the centralized systems. The MEPB is in charge of inspecting the systems, with an average inspection frequency of once a month. Users of the centralized systems include residents, industries, and farms. Moreover, for decentralized wastewater reuse systems, the property management company is mainly in charge of the daily operations and maintenance of the plants. Similarly, the MAC, representing the government, promotes the construction of the plants, and the MEPB inspects the plants twice a month on average. Users of the decentralized systems depend on the construction sites or institutes the plants serve, and such users mostly include residents, students, and hotel guests.

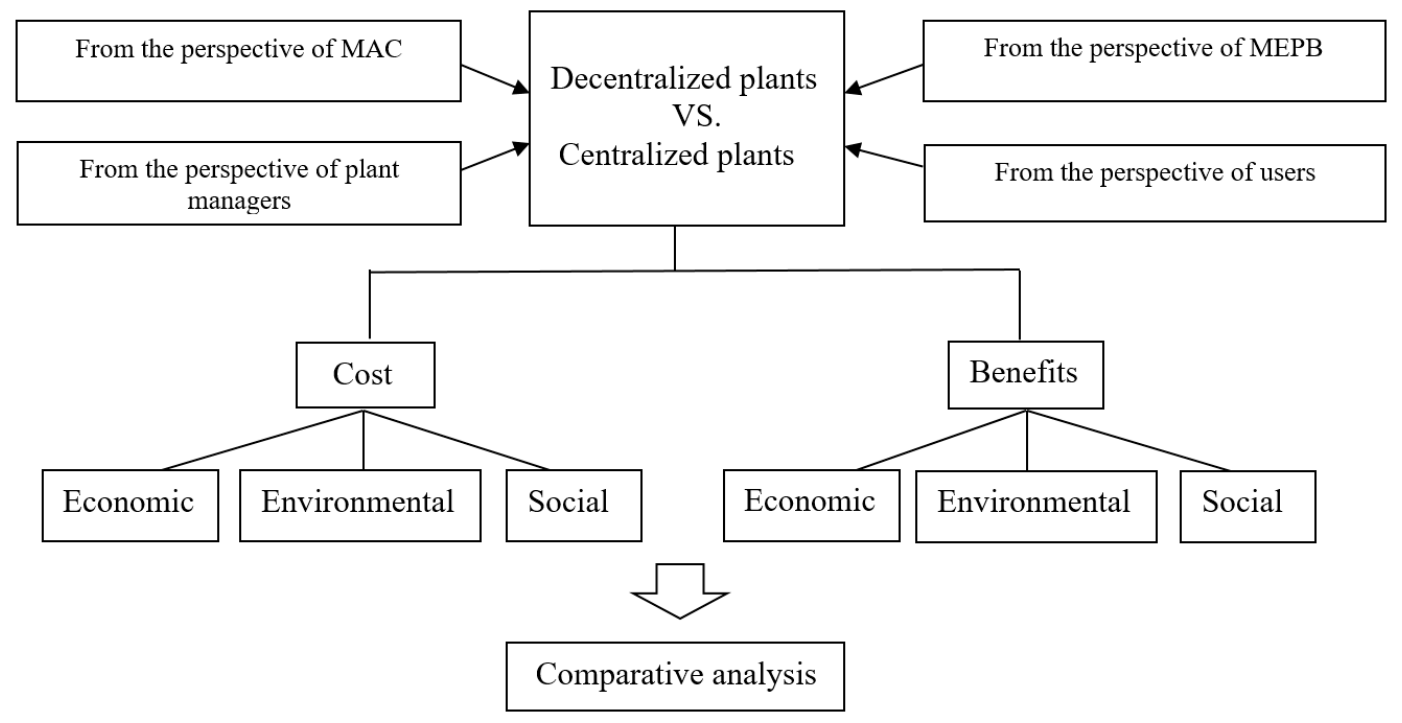

Figure 3. Evaluation framework.

The CBA approach is implemented from three perspectives: economic, environmental, and social effects. Accordingly, the economic, environmental, and social costs and benefits are determined using their monetary values. For effects such as economic costs, the monetary corresponding values can be directly determined according to their market prices. However, the monetary values of effects without market prices, such as environmental and social benefits, are determined through indirect valuation methods. In the CBA method, if the benefits and costs stretch over time, present values of the costs and benefits occurring in different periods are required. Because the water price has changed constantly in recent years, the estimation period selected in this study is from 2003 to 2013 . The key point of the study is to perform a comparative analysis; hence, the selected period should not bias the results.

Finally, a comparative analysis is implemented to achieve a thorough conclusion, and this analysis involves (1) comparing among the results from the perspectives of different stakeholders toward the centralized and decentralized systems; and (2) comparing between the centralized and decentralized systems. The quantitative cost benefit study facilitates this comparative analysis. 


\section{Analysis from the Perspectives of Different Stakeholders}

The interests of different stakeholders in wastewater reuse systems should be diverse. The study first presents potential cost and benefit factors according to the cases separately examined from the perspectives of four stakeholders. Subsequently, the evaluation method of each factor is introduced in detail. Notably, in the current study, not all cost and benefit factors are listed in the tables, but the significant factors are evaluated. The reasons of factors choosing are explained in the subsequent sections. All of the evaluated factors are symbolized by specific notations and presented in the tables in the subsequent sections. Moreover, the economic, environmental, and social cost benefit factors are presented on the basis of literature reviews and interviews [18-20].

\subsection{Perspective of the $M A C$}

From the perspective of the MAC, the contribution of wastewater reuse systems to society is emphasized. Therefore, the economic, environmental, and social effects of wastewater reuse systems are all considered. Table 1 indicates that the factors for the centralized and decentralized systems are different.

Table 1. Cost benefit factors from the perspective of the Municipal Administration Committee (MAC).

\begin{tabular}{|c|c|c|}
\hline & Centralized Systems & Decentralized Systems \\
\hline $\operatorname{Cost}\left(\mathrm{C}_{\mathrm{G}}\right)$ & $\begin{array}{c}\text { Initial investment }\left(I_{1}\right) \\
\text { O\&M cost }\left(M_{1}\right) \\
\text { Carbon dioxide emission }\left(E_{1}\right) \\
\text { Health risk }\left(H_{1}\right) \\
\text { Residential resettlement }\left(V_{1}\right) \\
\text { Noise pollution } \\
\text { Air pollution }\end{array}$ & $\begin{array}{l}\text { Initial investment }\left(I_{2}\right) \\
\text { O\&M cost }\left(M_{2}\right) \\
\text { Noise pollution }\left(\mathrm{N}_{2}\right) \\
\text { Health risk }\left(\mathrm{H}_{2}\right) \\
\text { Air pollution }\end{array}$ \\
\hline Benefits $\left(\mathrm{B}_{\mathrm{G}}\right)$ & $\begin{array}{c}\text { Cost saving on fertilizers }\left(L_{1}\right) \\
\text { Increase of water availability }\left(O_{1}\right) \\
\text { Increase of jobs }\left(J_{1}\right) \\
\text { Reuse of pollutants } \\
\text { Raising social awareness }\end{array}$ & $\begin{array}{c}\text { Cost savings on constructing pipes }\left(X_{2}\right) \\
\text { Increase in water availability }\left(\mathrm{O}_{2}\right) \\
\text { Raising social awareness }\left(A_{2}\right) \\
\text { Cost saving on water distribution } \\
\text { Cost saving on water purification }\end{array}$ \\
\hline
\end{tabular}

\subsubsection{Centralized Systems}

\section{Cost Evaluation}

From the perspective of the MAC, a centralized system can engender the economic costs of initial investment and O\&M cost, the environmental costs of carbon dioxide emission, noise pollution and air pollution, and the social costs of health risk and residential resettlement. The detailed explanation is as follows.

First, initial investment and O\&M cost are included in the economic cost evaluation. Since there are not many trade items in initial investment and O\&M cost, the market prices of investment and O\&M cost have not large distortions and could be used as the economic values directly. The initial investments of plant 3 and 4 are CNY $¥ 300$ million and CNY $¥ 77$ million.

Second, because centralized wastewater reuse systems generally involve large-scale wastewater treatment, the energy consumption associated with wastewater reuse is considerable. The energy generation process involves high carbon dioxide emission rates, leading to high environmental cost. Other emissions such as sulfur dioxide and nitrogen oxides are also made during energy generation, but carbon dioxide emission accounts for around $60 \%$ of total emission [21]. To simplify the study, only the effect of carbon dioxide is taken into consideration. In terms of the literature, $70 \%$ of energy consumption in China is from coal power [22]. Therefore, it is assumed that $70 \%$ of the energy for centralized wastewater reuse plants in Beijing comes from coal power, which is considered for 
evaluation of carbon dioxide emission in the study. Due to the small quantity, the environmental cost by the remaining $30 \%$ of energy generation is neglected. The total amount of carbon dioxide emission due to energy consumption could be obtained through multiplying $70 \%$ of the energy consumption and carbon dioxide emission rate. The primary environmental effect of carbon dioxide emission is climate change. However, it is complex and difficult to estimate the social impact of carbon dioxide because of its uncertainty. Tol (2005) have estimated that the mean damage cost of carbon dioxide is US $\$ 50 /$ ton (CNY $¥ 350 /$ ton), which can be used in the study [23]. Hence, the environmental cost of carbon dioxide emission (defined as $E_{1}$ ) can be obtained by Equation (1):

$$
E_{1}=b \times g \times z \times 70 \%
$$

where $b$ is the unit cost per carbon dioxide emission, being CNY $¥ 350 /$ ton [23]; $g$ is the energy consumption of the plant (kWh/year); $z$ is the carbon dioxide emission rate, being approximately $800 \mathrm{~g} / \mathrm{kWh}$ [21].

Third, the reused water may contain a certain amount of pathogens; therefore, using the water for green and agricultural irrigation may cause negative effects on human health directly or indirectly, leading to health risks, which can be considered a social cost $[24,25]$. Various methods have been carried out to value health risk, such as contingent valuation methodology and adjusted human capital methodology. These economic methods have to be applied to big samples with a large amount of data, because of inherent limitations. We apply an indirect valuation method through the disability-adjusted life year (DALY) index. The Disability Adjusted Life Year (DALY) index is a measurement unit for the effect on human health, developed by the World Health Organization (WHO) and the World Bank. 1 DALY corresponds to 1 year of healthy life lost, and the total burden of diseases can be measured according to the gap between current health status and an ideal situation in which everyone lives with no diseases or disabilities [26]. DALY has been applied in lots of studies on health risk. For example, Aramaki et al. (2006) found that after building wastewater treatment units, the disease burden of a community changed from 60 to 5.7 DALYs per year [27]. In the current study, the DALY index is used as a bridge to convert the monetary value of health effects from the national level to the scope of a wastewater reuse plant. Moreover, diarrhea is regarded to be the largest contributor to the burden of water-related illnesses (OECD, 2007). The health risk caused by wastewater reuse in this study is limited to diarrhea. We assumed that the DALYs of Beijing resulting in diarrhea is caused by reused wastewater. Therefore, the social cost of diarrhea due to wastewater reuse plant could be regarded as the cost of health risk (defined as $H_{1}$ ), which is calculated by using Equation (2):

$$
H_{1}=d \times q \times k \times p_{1}
$$

where $d$ is the DALY cost rate, being CNY $¥ 2813$ per DALY per year [28,29]; $q$ is the DALY rate, as a result of missing data, the DALYs rate of Beijing is determined by the DALYs rate of China, which is $389 \times 10^{-5}$ DALYs per person [28]; $k$ is the registered permanent population living in Beijing central district, being 2.25 million; $p_{1}$ is the DALY probability associated with the centralized wastewater reuse plant, which can be represented by the ratio of the reused water amount for greening and agricultural irrigation to the total amount of reused water in Beijing $(\%)$.

Fourth, according to interviews conducted with officials of the Beijing Water Authority, $60 \%$ of the distribution pipes of centralized wastewater reuse systems are constructed through demolition and relocation. Demolition and relocation can lead to changes in the road net, the destruction of existing city buildings and residential resettlement [30]. It is rare in the literature that all social costs of demolition and relocation are evaluated completely because of the extreme difficulty on quantifying. Residential resettlement is the most important one among the effects caused by demolition and relocation, as it can induce various negative effects such as unemployment and increased living and transportation costs [31]. Therefore, for simplifying the evaluation, only the effect of residential resettlement is considered. Residential resettlement means residents living along the line of pipe construction must move to other places. As public transportation is the main travel method for Beijing 
residents, all relocated residents may suffer from an increased transportation cost. While, other effects such as unemployment and increased educational cost may not occur to some relocated residents. Increased transportation cost causes an essential and real effect on people's lives [30,31]. Hence the increased transportation cost is used to determine the cost of residential resettlement(defined as $V_{1}$ ) in this study, which can be derived using Equation (3):

$$
V_{1}=t \times p \times l
$$

where $t$ is the average increased public transport cost for one person, being CNY $¥ 4$ per person per day; It is assumed that all affected residents make one additional transfer each day via public transportation (including metro and bus); The additional transfer cost is regarded as the increased public transport cost; $p$ is the population density of Beijing, being around 20,000 persons per square meter [32]; $l$ is the length of pipe construction (meter); It assumes that the width of pipe construction is $1 \mathrm{~m}$.

However, the cost factors of noise and air pollution are not considered in this study. The studied plants are located in suburban areas with few residents. Although the noise and unpleasant smell are generated by the wastewater reuse plants, they cannot cause significant effects on society. Therefore, the influences caused by noise and unpleasant smell could be neglected.

Therefore, the total cost (defined as $C_{G 1}$ ) of centralized wastewater reuse plants can be determined by Equation (4):

$$
C_{G 1}=I_{1}+\sum_{t=1}^{n} \frac{M_{1}}{(1+r)^{t}}+\sum_{t=1}^{n} \frac{E_{1}}{(1+r)^{t}}+\sum_{t=1}^{n} \frac{H_{1}}{(1+r)^{t}}+\sum_{t=1}^{n} \frac{V_{1}}{(1+r)^{t}}
$$

where $I_{1}$ is the initial investment of centralized plant (CNY $\left.¥\right), M_{1}$ is the O\&M cost of centralized plant (CNY $¥$ per year); $r$ is the discounting rate, being $8 \%$; According to the publication of National Development Reform and Commission "Chinese Economic Evaluation Parameters on Construction" (2006), the nominal discount rate used for benefit cost studies in China is $8 \%$ which is determined by the social economic growth, the expected inflation rate and opportunity cost of capital; $n$ is the period, which is assumed to be 10 years: 2003-2013.

\section{Benefits Evaluation}

From the perspective of the MAC, the benefits of centralized wastewater reuse systems involve cost savings on fertilizers, increased water availability, increased jobs, reuse of pollutants, and raising social awareness.

First, regarding the evaluation of benefits, applying reused water for agricultural irrigation limits the use of fertilizers in agricultural production because reused water contains nitrogen and phosphorus, which are crucial fertilizers for agricultural production [33]. The cost saving on fertilizers is regarded as the economic benefits of centralized wastewater reuse (defined as $L_{1}$ ), which can be determined by Equation (5):

$$
L_{1}=u_{f} \times f
$$

where $u_{f}$ is the unit cost of saving on fertilizers, being approximately CNY $¥ 0.0225 / \mathrm{m}^{3}$ [34]; It is calculated by Beijing Water Authority through dividing the increase of agriculture production by the total amount of reused water for agriculture irrigation; $f$ is the amount of reused water for agricultural irrigation, $f$ for the plant 3 and 4 is $30,000 \mathrm{~m}^{3}$ and $3000 \mathrm{~m}^{3}$ each day separately.

Second, increased water availability is the most vital environmental benefit engendered by the centralized wastewater reuse systems. The benefit associated with increased water availability (defined as $O_{1}$ ) could be determined by Equation (6):

$$
O_{1}=u_{e} \times e_{1}
$$

where $u_{e}$ is the monetary value of water, being $\mathrm{CNY} ¥ 9 / \mathrm{m}^{3}$ [35]; Some studies use a small range of data for the estimation of water shadow price in China, leading to a nonrigorous value [36,37]; 
Compared with other studies, Liu and Zou (2014) take extensive data for their estimation, including data from the nine major Chinese river basins and data from agriculture, industry, commerce and service, and thus its result is used in the study [37]; $e_{1}$ is the amount of reused water, $e_{1}$ for plant 3 and 4 is $470,000 \mathrm{~m}^{3}$ and $60,000 \mathrm{~m}^{3}$ each day separately.

Third, the operation of centralized wastewater reuse systems typically requires many workers, thus resulting in the creation of numerous jobs and the improvement of the employment rate of the regions containing such systems. The social benefit of employment increase can be determined through employment elasticity which is a ratio of employment growth to economic growth. If the employment elasticity is 0.1 , that means an economic growth of $1 \%$ increases employment by $0.1 \%$ [38]. There are many research discussing the employment elasticity of China. Largely the employment elasticity of the eastern China is estimated to be around 0.3, which is taken to present the employment elasticity of Beijing, because of data limitation [38,39]. It is assumed that the economic growth related to employment increase could be the social benefit value of job creation. The social benefit (defined as $J_{1}$ ) can be determined by Equation (7):

$$
J_{1}=\frac{\frac{w}{W}}{\beta} \times Y
$$

where is $\beta$ is the ratio of employment growth to economic growth, being $0.3[38,39]$; $w$ is the number of increased jobs in the plant, $w$ for plant 3 and 4 is 30 and 20 persons separately; $W$ is the total employment amount of Beijing (person); and $Y$ is the gross domestic product of Beijing (CNY $¥$ ).

For centralized wastewater reuse system, methane gas produced in anaerobic digestion and pollutants of wastewater reuse systems in Beijing are not reused; consequently, the benefits of the reuse of pollutants are not considered in the study. Moreover, users do not readily gain a clear perception of whether the water is tap water or reused water because the reused water can be obtained easily from direct distribution. Therefore, the benefit of raising social awareness is not evaluated. The total benefits of centralized systems (defined as $B_{G 1}$ ) is determined through Equation (8). It is similar to the cost evaluation that the present values of benefits are calculated.

$$
B_{G 1}=\sum_{t=1}^{n} \frac{L_{1}}{(1+r)^{t}}+\sum_{t=1}^{n} \frac{O_{1}}{(1+r)^{t}}+\sum_{t=1}^{n} \frac{J_{1}}{(1+r)^{t}}
$$

\subsubsection{Decentralized Systems}

\section{Cost Evaluation}

From the viewpoint of the government, decentralized systems may engender initial investment costs, O\&M costs, health risks, noise pollution, and air pollution. Similar to the centralized systems, the initial investment and O\&M costs are essential costs to society, and they should thus be considered. The initial investment cost of plant 1 and 2 are CNY $¥ 3.5$ million and CNY $¥ 5$ million.

Second, as decentralized systems are generally constructed close to residents, the noise and unpleasant smell generated during wastewater treatment processes can cause negative effects. However, the unpleasant smell can be eliminated through the use of ventilation systems, thereby reducing the effects on the residents. Hence, this study evaluates only noise pollution. It is too complicated to estimate the noise pollution directly, and thus the result of the literature is employed. Liu (1999) finds that the noise pollution cost in Dalian city is around CNY $¥ 108$ per person each year [40]. Because the evaluation period of this study is from 2003 to 2013, the estimated noise pollution cost by Liu (1999) could be used. According to the statistical yearbook, the income of Beijing's resident is 1.5 times higher than the income of Dalian's resident. Moreover, the ratio of the consumption of Beijing to Dalian is also 1.5. Therefore, we assume that the noise pollution cost of Beijing is 1.5 times higher than the one of Dalian city. The noise pollution cost in Beijing is determined to be CNY $¥ 162$ per person per year. Therefore, the environmental cost of noise (defined as $N_{2}$ ) can be derived by Equation (9). 


$$
N_{2}=C_{u} \times u
$$

where $C_{u}$ is the unit noise pollution cost, being CNY $¥ 162$ per person per year; $u$ is the number of affected people due to the plant (person).

Third, similar to the centralized systems, using the reused water from the decentralized systems for toilet flushing and green land irrigation may lead to human health risks. The determination method has been explained in the cost evaluation of centralized plants. The cost of health risks of decentralized plants (defined as $\mathrm{H}_{2}$ ) can be calculated by Equation (10):

$$
H_{2}=d \times k \times q \times p_{2}
$$

where $p_{2}$ is probability of DALY associated with the decentralized wastewater reuse plants (\%).

Therefore, the total cost of the decentralized plant (defined as $C_{G 2}$ ) can be calculated as follows:

$$
C_{G 2}=I_{2}+\sum_{t=1}^{n} \frac{M_{2}}{(1+r)^{t}}+\sum_{t=1}^{n} \frac{N_{2}}{(1+r)^{t}}+\sum_{t=1}^{n} \frac{H_{2}}{(1+r)^{t}}
$$

where $I_{2}$ is the initial investment of decentralized plant (CNY $\left.¥\right) ; M_{2}$ is the O\&M cost of decentralized plant (CNY $¥$ per year).

\section{Benefits Evaluation}

Regarding the evaluation of benefits, the benefits of a decentralized system comprise cost savings on constructing pipes, cost savings on water distribution, cost savings on water purification, increased water availability, and raising social awareness. Compared with centralized wastewater reuse systems, decentralized systems require shorter distribution pipes for reclaimed water, thus reducing the considerable costs associated with pipe construction. Because the capacity of a decentralized system is generally limited, the cost savings on water purification and distribution are extremely small and can be ignored in the current analysis. Therefore, only the benefit of cost saving on constructing pipe (defined as $X_{2}$ ) is considered, which can be determined by Equation (12):

$$
X_{2}=C_{L} \times L
$$

where $C_{L}$ is the unit pipe construction cost, being CNY $¥ 2000$ per meter; According to interviews with officials of the Beijing drainage group, the unit value of pipe construction cost is between CNY $¥ 2000$ and 20,000 per meter; We take the least unit cost value CNY $¥ 2000$ per meter; $L$ is the pipe length (meter), determined by the distance between the closest centralized plant and the studied decentralized plant which is also the location of user; It assumes that the reclaimed water would be provided by the closest centralized plant, if no decentralized plant is available.

Similar to centralized plants, the benefit engendered by increased water availability (defined as $\mathrm{O}_{2}$ ) can be determined by multiplying the monetary value of water $\left(u_{e}\right)$ by the amount of reused water, as presented in Equation (13):

$$
\mathrm{O}_{2}=u_{e} \times e_{2}
$$

where $e_{2}$ is the reused water amount of decentralized plant, $e_{2}$ for plant 1 and 2 is $65 \mathrm{~m}^{3}$ and $400 \mathrm{~m}^{3}$.

Finally, decentralized systems are established beside construction sites or in living areas. Users in such areas are adequately informed about the existence of wastewater reuse plants nearby and can use the reused water. Such information enhances users' awareness concerning water saving, resulting in cost savings on the implementation of awareness rising campaigns. Therefore, the cost savings on campaigns can be regarded as the social benefits of raising social awareness on water saving (defined as $A_{2}$ ), which is determined by Equation (14):

$$
A_{2}=a \times j
$$


where $a$ is the average cost of public campaign in water sector in Beijing, being around CNY $¥ 2,780,000$ each year [41]; $j$ is the ratio of number of users to the total population of Beijing (\%).

Therefore, the total benefit of a decentralized plant (defined as $B_{G 2}$ ) can be calculated by using Equation (15):

$$
B_{G 2}=X_{2}+\sum_{t=1}^{n} \frac{O_{2}}{(1+r)^{t}}+\sum_{t=1}^{n} \frac{A_{2}}{(1+r)^{t}}
$$

\subsection{Perspective of the $M E P B$}

As one of the stakeholders involved in wastewater plant management, the MEPB focuses on the environmental effects of wastewater reuse systems. The cost benefit factors are shown in Table 2. To the best of our knowledge, wastewater reuse systems can effectively save water resources, leading to the environmental benefit of increased water availability. Nevertheless, such plants can induce negative environmental effects. Centralized systems can produce high energy consumption as well as noise and air pollution, whereas decentralized systems can engender noise and air pollution. As mentioned previously, the noise pollution and air pollution levels generated by the centralized systems in the studied cases are extremely low and thus neglected. The air pollution generated by the decentralized systems is also not significant in the study.

Table 2. Cost benefit factors from the perspective of the MEPB.

\begin{tabular}{ccc}
\hline & Centralized Systems & Decentralized Systems \\
\hline \multirow{2}{*}{$\operatorname{Cost}\left(C_{E}\right)$} & Carbon dioxide emission $\left(E_{1}\right)$ & Noise pollution $\left(N_{1}\right)$ \\
& $\begin{array}{c}\text { Noise pollution } \\
\text { Air pollution }\end{array}$ & Air pollution \\
\hline Benefits $\left(B_{E}\right)$ & Increase of water availability $\left(O_{1}\right)$ & Increase in water availability $\left(O_{2}\right)$ \\
\hline
\end{tabular}

\subsubsection{Centralized Systems}

The cost $C_{E 1}=\sum_{t=1}^{n} \frac{E_{1}}{(1+r)^{t}}$, the estimation of $E_{1}$ is shown in Equation (1); and the benefit $B_{E 1}=\sum_{t=1}^{n} \frac{O_{1}}{(1+r)^{t}}$, the estimation of $O_{1}$ is shown in Equation (6).

\subsubsection{Decentralized Systems}

The cost $C_{E 2}=\sum_{t=1}^{n} \frac{N_{2}}{(1+r)^{t}}$, the estimation of $N_{2}$ is indicated in Equation (9); and the benefit $B_{E 2}=\sum_{t=1}^{n} \frac{\mathrm{O}_{2}}{(1+r)^{t}}$, the estimation of $\mathrm{O}_{2}$ is shown in Equation (13).

\subsection{Perspective of Plant Managers}

From the perspective of plant managers, the financial performance of plants is their main concern. Specifically, plant managers consider only economic factors, rarely paying attention to environmental and social effects. As shown in Table 3, the centralized and decentralized systems possess the same cost factors. The costs include initial investment and O\&M costs. The initial investment costs of the centralized systems include the costs of construction, demolition and relocation, preparation, interests, and others, whereas those of the decentralized systems include only the initial cost of construction.

The benefits of centralized and decentralized systems are both represented by the revenue from reused water charges and subsidies (Table 3 ). The usage of the reused water is charged at different rates set by the government (shown in Table 4, which consists of the revenues of plant managers. For most of the decentralized systems in Beijing, the buildings and equipment are subsidized; in certain instances, the O\&M cost is also subsidized yearly such as plant 2 getting the subsidies of CNY $¥ 146,000$ per year. 
Some centralized systems gain subsidies on their initial investment costs. For example, plant 1 and plant 3 are subsided CNY $¥ 0.3$ million and 123 million at one time.

Table 3. Cost benefit factors from the perspective of plant managers.

\begin{tabular}{ccc}
\hline & Centralized Systems & Decentralized Systems \\
\hline \multirow{2}{*}{ Cost $\left(C_{P}\right)$} & Initial investment $\left(I_{1}\right)$ & Initial investment $\left(I_{2}\right)$ \\
& O\&M cost $\left(M_{1}\right)$ & O\&M cost $\left(M_{2}\right)$ \\
\hline \multirow{2}{*}{ Benefits $\left(B_{P}\right)$} & Revenue $\left(R_{1}\right)$ & Revenue $\left(R_{2}\right)$ \\
& Subsidies $\left(S_{1}\right)$ & Subsidies $\left(S_{2}\right)$ \\
\hline
\end{tabular}

Table 4. Comparison of reused water and municipal tap water price $\left(\mathrm{CNY} ¥ / \mathrm{m}^{3}\right)$.

\begin{tabular}{ccccc}
\hline & Domestic & Landscape & Industrial & Power Generating Plant \\
\hline Reused water & 1 & 0.9 & 1.5 & 0.9 \\
\hline Municipal water & 4 & 4 & 4.5 & 4.5 \\
\hline
\end{tabular}

\subsubsection{Centralized Systems}

The cost (defined as $C_{P 1}$ ) can be calculated using Equation (16):

$$
C_{P 1}=I_{1}+\sum_{t=1}^{n} \frac{M_{1}}{(1+r)^{t}}
$$

The benefits (defined as $B_{P 1}$ ) can be calculated using Equation (17). Plant 1 obtains subsidies for initial investment while plant 2 have not subsidies.

$$
B_{P 1}=\sum_{t=1}^{n} \frac{R_{1}}{(1+r)^{t}}+S_{1}
$$

\subsubsection{Decentralized Systems}

The cost (defined as $C_{P 2}$ ) can be calculated using Equation (18):

$$
C_{P 2}=I_{2}+\sum_{t=1}^{n} \frac{M_{2}}{(1+r)^{t}}
$$

The benefits (defined as $B_{P 2}$ ) can be calculated using Equation (19). Plant 3 is subsidized for initial investment, while plant 4 is subsidized each year.

$$
B_{P 2}=\sum_{t=1}^{n} \frac{R_{2}}{(1+r)^{t}}+\sum_{t=1}^{n} \frac{S_{2}}{(1+r)^{t}}
$$

\subsection{Perspective of Users}

From the perspective of users, money saving through the use of reused water is the main benefit, and health risk, noise and air pollution is the main cost, as shown in Table 5. Because users of the centralized systems are located anywhere in the city, they incur only health risks associated with the use of the reused water. However, those of the decentralized systems reside beside the plants; the plants can expose the users to noise pollution, unpleasant smell, and health risks. In this study, the unpleasant smells have no considerable effects on users and are thus neglected. 
Table 5. Cost benefit factors from the perspective of users.

\begin{tabular}{ccc}
\hline & Centralized Systems & Decentralized Systems \\
\hline \multirow{2}{*}{ Cost $\left(C_{P}\right)$} & Health risk $\left(H_{1}\right)$ & Noise pollution $\left(N_{2}\right)$ \\
& & Health risk $\left(H_{2}\right)$ \\
& Air pollution \\
\hline Benefits $\left(B_{P}\right)$ & Money saving $\left(m_{1}\right)$ & Money saving $\left(m_{2}\right)$ \\
\hline
\end{tabular}

Table 4 lists the price difference between reused water and municipal tap water in Beijing in 2013 , signifying that the average difference is approximately CNY $¥ 3 / \mathrm{m}^{3}$. Users are charged the same price for the use of reused water, regardless of whether the water is obtained from the centralized or decentralized systems. Hence, for both the centralized and decentralized systems, the benefits of money saving (defined as $m_{1}$ and $m_{2}$ ) are the same, that is $m_{1}=m_{2}$, which is CNY $¥ 3 / \mathrm{m}^{3}$. However, the users of plant 2 do not receive benefits, as the users are university students and faculties who do not need to pay for the reused water.

\subsubsection{Centralized Systems}

The cost (defined as $C_{U 1}$ ) can be calculated as shown in Equation (20):

$$
C_{U 1}=H_{1} / Q_{1}
$$

where $Q_{1}$ is the amount of reused water of centralized plants for domestic and landscape usage; $H_{1}$ is the cost of health risks which is evaluated by Equation (2).

The benefit (defined as $B_{U 1}$ ) can be determined using Equation (21):

$$
B_{U 1}=m_{1}
$$

\subsubsection{Decentralized Systems}

The cost (defined as $C_{U 2}$ ) can be calculated through Equation (22):

$$
C_{U 2}=\frac{N_{2}+H_{2}}{Q_{2}}
$$

where $Q_{2}$ is the amount of reused water of decentralized plants for residential and landscape usage; $\mathrm{N}_{2}$ is the environmental cost of noise (calculated by Equation (9)); and $\mathrm{H}_{2}$ is the cost of health risks (calculated by Equation (10)).

The benefit (defined as $B_{U 2}$ ) can be determined through Equation (23):

$$
B_{U 2}=m_{2}
$$

\section{Results and Comparative Analysis}

The quantitative analysis results are used to conduct comparative analyses, which are divided into two parts: comparison among the results of different stakeholders and comparison between the centralized and decentralized wastewater reuse systems. Table 6 presents the cost and benefit values, ratio of benefits to costs, and economic feasibility of each studied plant, which are determined by the equations introduced in Section 4. The economic feasibility depends on the benefit cost ratio: If the ratio is higher than 1, the concerned plant is considered economically feasible; otherwise, it is not economically feasible. For comparing easily, all results are represented by unit value, namely total values are divided by reused water amount $\left(\mathrm{CNY} ¥ / \mathrm{m}^{3}\right)$. 
Table 6. Results of quantitative analysis.

\begin{tabular}{|c|c|c|c|c|}
\hline & \multicolumn{2}{|c|}{ Decentralized Plants } & \multicolumn{2}{|c|}{ Centralized Plants } \\
\hline & Plant 1 & Plant 2 & Plant 3 & Plant 4 \\
\hline Capacity $\left(\mathrm{m}^{3} /\right.$ day) & 65 & 400 & 470,000 & 60,000 \\
\hline \multicolumn{5}{|l|}{ From the perspective of MAC } \\
\hline Cost $\left(\mathrm{CNY} ¥ / \mathrm{m}^{3}\right)$ & 14.8 & 3.4 & 0.4 & 0.5 \\
\hline Benefits(CNY $\left.¥ / \mathrm{m}^{3}\right)$ & 67 & 18.5 & 3 & 3 \\
\hline Ratio of benefits to cost & 4.5 & 5.4 & 7.5 & 6 \\
\hline Economically feasible & Yes & Yes & Yes & Yes \\
\hline \multicolumn{5}{|c|}{ From the perspective of $M E P B$} \\
\hline Cost $\left(\mathrm{CNY} ¥ / \mathrm{m}^{3}\right)$ & 0.14 & 0.007 & 0.009 & 0.0009 \\
\hline Benefits (CNY $¥ / \mathrm{m}^{3}$ ) & 1.7 & 1.93 & 1.47 & 1.47 \\
\hline Ratio of benefits to cost & 12.35 & 259 & 167 & 1697 \\
\hline Economically feasible & Yes & Yes & Yes & Yes \\
\hline \multicolumn{5}{|c|}{ From the perspective of plant managers } \\
\hline Cost $\left(\mathrm{CNY} ¥ / \mathrm{m}^{3}\right)$ & 14.5 & 3.5 & 0.39 & 0.5 \\
\hline Benefits (CNY $\left.¥ / \mathrm{m}^{3}\right)$ & 1.9 & 1.3 & 0.6 & 0.9 \\
\hline Ratio of benefits to cost & 0.13 & 0.37 & 1.5 & 1.8 \\
\hline Economically feasible & No & No & Yes & Yes \\
\hline \multicolumn{5}{|l|}{ From the perspective of users } \\
\hline Cost $\left(\mathrm{CNY} ¥ / \mathrm{m}^{3}\right)$ & 0.34 & 0.02 & 0.05 & 0.02 \\
\hline Benefits (CNY $\left.¥ / \mathrm{m}^{3}\right)$ & 3 & 0 & 3 & 3 \\
\hline Ratio of benefits to cost & 8.8 & 0 & 60 & 150 \\
\hline Economically feasible & Yes & No & Yes & Yes \\
\hline
\end{tabular}

\subsection{Comparison among Different Stakeholders}

Table 6 indicates that the results derived from the perspectives of the MAC and MEPB are similar, whereas those derived from the viewpoints of plant managers and users are different. From the perspectives of the MAC and MEPB, both centralized and decentralized wastewater plants are economically feasible. The MAC has extensively promoted wastewater reuse systems because such plants positively influence society. Moreover, both wastewater reuse systems evaluated in this study are environmentally friendly because the environmental benefits are considerably higher than the costs. From the perspective of the MEPB, the benefit cost ratios are higher, particularly for middle-sized plants such as plant 2 (capacity: $400 \mathrm{~m}^{3}$ ) and plant 4 (capacity: 60,000 $\mathrm{m}^{3}$ ).

From the perspective of plant managers, the ratios of the centralized plants are higher than 1 , whereas those of the decentralized plants are lower than 1 . The management of plants 3 and 4 can obtain benefits of CNY $¥ 0.6 / \mathrm{m}^{3}$ and CNY $¥ 0.9 / \mathrm{m}^{3}$. Although the benefits are low, the costs of plants 3 and 4 are only CNY $¥ 0.39 / \mathrm{m}^{3}$ and CNY $¥ 0.5 / \mathrm{m}^{3}$. The situations of the decentralized plants are opposite; that is, they have higher costs and lower benefits. For decentralized plants, the ratios of benefits to cost are separately 0.13 and 0.37 which are less than 1 . This means that plant managers cannot make profits when operating decentralized plants. They have not incentives to continue the operation of decentralized wastewater reused plants.

Regarding users, the incentive on reused water relies on the high benefit cost ratios. The price gap between reused water and municipal tap water in Beijing is CNY $¥ 3 / \mathrm{m}^{3}$, which is sufficiently high to attract users to reused water. Users including residents, industries, and electricity plants can save a certain amount of money by using reused water. Therefore, they support and pay attention to wastewater reuse systems in Beijing to save money, although they may incur noise pollution and health risks. Nevertheless, the users of plant 2 are university students and faculties, who are not charged; they do not derive any benefits, despite incurring noise pollution and health risks. Consequently, users in public institutes would not have any interests toward wastewater reuse systems. 
For saving water, the MAC has extensively promoted wastewater reuse systems. Although such systems may cause various effects such as noise pollution, energy costs, and residential resettlement, they exert positive effects on society. From the perspective of the MEPB, wastewater reuse systems are environmentally friendly. However, plant managers and users of decentralized systems have different opinions from the MAC and MEPB. Low benefit cost ratios diminish the incentives of plant managers to manage such systems as well as the interests of users to actually use the systems. This may be one of the reasons for the failure of the operation of decentralized systems in Beijing, thus preventing the objective of water saving through decentralized wastewater reuse systems from being realized.

Failure to satisfy parts of stakeholders' main interests hinders the smooth operation of a new system. In general, in China, new environmental management systems are extensively promoted without the execution of integrated or systematical estimation and verification procedures, thus resulting in the unsustainable operation of such systems. Consequently, the substantial amount of capital for initial investment and operation is wasted, and the objective of sustainable management cannot be realized.

\subsection{Comparison between Centralized and Decentralized Systems}

Table 6 also indicates that from the perspective of the MAC, the benefit cost ratios of the four examined plants are close and higher than 1, implying that the Beijing decentralized systems have the same positive contribution to society as the centralized systems. Accordingly, promoting both centralized and decentralized systems is warranted.

From the perspective of the MEPB, plants 2 and 4 have higher benefit cost ratios than do the other plants. Plant 1 creates a lower amount of reused water, in addition to exposing users to certain levels of noise pollution and health risks. Plant 3 creates a high volume of reused water, but consumes a substantial amount of energy. Therefore, regarding environmental effects, large decentralized plants and small centralized plants are more feasible.

Because of the scale of the economy, the costs of centralized plants are considerably lower than that of decentralized plants, as observed from the perspective of plant managers. For example, the economic cost of plant 1 (decentralized plant) is CNY $¥ 14.5 / \mathrm{m}^{3}$, whereas that of plant 3 (centralized plant) is only CNY $¥ 0.39 / \mathrm{m}^{3}$ (Table 6). Although decentralized plants can obtain subsidies for initial investment costs, the reused water price is not sufficiently high to cover the costs.

The price charged for the use of reused water is approximately CNY $¥ 1 / \mathrm{m}^{3}$, regardless of whether the water is sourced from centralized or decentralized plants. Hence, users can obtain the same benefit from both plant types. Because of their on-site establishment, decentralized plants may engender noise and air pollution. Consequently, users of decentralized plants incur slightly higher costs, compared with those of centralized plants. For example, the user cost for plant 1 (decentralized plant) is CNY $¥ 0.34 / \mathrm{m}^{3}$ and that for plant 3 (centralized plant) is CNY $¥ 0.05 / \mathrm{m}^{3}$ (Table 6). Except for plant 2, the centralized and decentralized plants have positive benefit cost ratios. The water from plant 2 is provided to users free of charge. The O\&M cost of plant 2 totally relies on subsidies, which may be unsustainable. Because of the lack of benefits, the users of plant 2 have no incentive to support the plant operation and use the reused water. Therefore, the sustainability of plant 2 is difficult to achieve. However, centralized plants do not encounter this type of obstruction. Although certain users may be not charged, other users pay the water fee continually. Not the subsidies are unsustainable but the plants. Hence, depending on subsidies for plants' operation is not sustainable in the long run.

In general, comparing the economic feasibility results from perspectives of the various stakeholders between the centralized and decentralized wastewater reuse systems reveals that the Beijing centralized systems are more economically feasible than the decentralized systems. For the centralized systems, the analysis results of all stakeholders demonstrate that the plants are economically feasible, whereas for decentralized systems, only the results of the MAC and MEPB reveal that the plants are economically feasible. In Beijing, the operation of centralized systems is smoother and more successful than that of decentralized systems in practice. Decentralized systems are confronted with 
three obstacles: (1) Not all stakeholders are satisfied; (2) charges for the reused water cannot cover the costs; and (3) certain decentralized systems completely depend on subsidies for their operations, which are unsustainable.

\section{Conclusions}

The paper quantitatively evaluates the interests of different stakeholders of wastewater reuse systems in Beijing. Such interests comprise economic, environmental, and social effects induced by the centralized and decentralized wastewater reuse systems. In the case of Beijing, four main stakeholders are considered, namely the MAC, MEPB, plant managers, and users. The CBA method is applied to determine the mentioned separately from the perspectives of various stakeholders, and economic feasibility is used as the criterion to justify whether the stakeholders' interests are satisfied, which is determined through benefit cost ratios.

The evaluation results show that not all the stakeholders' interests in wastewater reuse in Beijing are satisfied. The interests of the MAC and MEPB are satisfied; while the interests of the plant managers and users are not satisfied. From the perspectives of plant managers and users of decentralized plants, numerous problems are encountered, such as high unit economic costs, unsustainable subsidies, and insufficient user incentives, which consequently hamper the sustainability of decentralized systems. Although the MAC has extensively promoted decentralized systems for many years in Beijing, the operations of decentralized systems are not highly successful and smooth. The failure to satisfy the interests of plant managers and users is a major reason for the interrupted operation of decentralized systems.

The study of Beijing's wastewater reuse systems demonstrates that successful and sustainable development of a new water project requires satisfying the interests of all stakeholders. If the interest of one of the main stakeholders is not considered, the project may be suspended or fail. Numerous new water projects have recently been promoted and implemented by the MAC for solving water scarcity in China. If the concerns of private mangers or users of the new projects are neglected as usual, these new projects may not operate smoothly and continuously. Sustainable water management cannot only depend on the construction and technological improvement. The non-technological factors such as financial matter and user incentives should receive more attention from decision makers and researchers in future.

Supplementary Materials: The following are available online at www.mdpi.com/2071-1050/8/11/1098/s1, Table S1: Summary of the parameter used for determination of cost and benefits.

Acknowledgments: This research was funded by Natural Science Foundation of SZU (grant No. 201428) and Social Science Foundation of Guangdong Province (grant No. GD15YGL03). We are grateful to the anonymous reviewers for their insightful comments.

Author Contributions: The article was mainly written by Xiao Liang. Meine Pieter van Dijk provided many valuable comments.

Conflicts of Interest: The authors declare no conflict of interest.

\section{References}

1. Starkl, M.; Brunner, N. Feasibility versus sustainability in urban water management. J. Environ. Manag. 2004, 71, 245-260. [CrossRef] [PubMed]

2. Chen, W.; Bai, Y.; Zhang, W.; Lyu, S.; Jiao, W. Perceptions of different stakeholders on reclaimed water reuse: The case of Beijing, China. Sustainability 2015, 7, 9696-9710. [CrossRef]

3. Sa-nguanduan, N.; Nititvattananon, V. Strategic decision making for urban water reuse application: A case from Thailand. Desalination 2011, 268, 141-149. [CrossRef]

4. Derak, M.; Taiquib, L.; Aledoc, A.; Cortina, J. Similarities in stakeholder identification of restoration targets in a semiarid area. J. Arid Environ. 2016, 128, 30-39. [CrossRef]

5. Liang, X.; van Dijk, M.P. The Factors in the Decision to Continue Rainwater Harvesting Systems in Beijing to achieve Sustainable Water Management. Water 2016, 8, 7-18. [CrossRef] 
6. Bixio, D.; Thoeye, C.; de Koning, J.; Joksimovic, D.; Savic, D.; Wintgens, T.; Melin, T. Wastewater reuse in Europe. Desalination 2006, 187, 89-101. [CrossRef]

7. Ogoshi, M.; Suzuki, Y.; Asano, T. Water Reuse in Japan. Water Sci. Technol. 2001, 43, 17-23. [PubMed]

8. Yi, L.; Jiao, W.; Chen, X.; Chen, W. An overview of reclaimed water reuse in China. J. Environ. Sci. 2011, 23, 1585-1593. [CrossRef]

9. Liang, X.; van Dijk, M.P. Financial and economic feasibility of decentralized wastewater reuse systems in Beijing. Water Sci. Technol. 2010, 61, 1965-1973. [CrossRef] [PubMed]

10. Chang, D.; Ma, Z. Wastewater reclamation and reuse in Beijing: Influence factors and policy implications. Desalination 2012, 297, 72-78. [CrossRef]

11. Zhang, W.; Chen, W.; Jiao, W. Policy evaluation and analysis on reclaimed wastewater reuse in Beijing. Huan Jing Ke Xue Xue Bao/Acta Sci. Circumst. 2013, 33, 2862-2870.

12. Chen, Z.; Ngo, H.H.; Guo, W. A critical review on sustainability assessment of recycled water schemes. Sci. Total Environ. 2012, 426, 13-31. [CrossRef] [PubMed]

13. Fan, Y.; Chen, W.; Jiao, W.; Chang, A.C. Cost-benefit analysis of reclaimed wastewater reuses in Beijing. Desalination Water Treat. 2015, 53, 1224-1233. [CrossRef]

14. Menikpura, S.N.M.; Gheewala, S.H.; Bonnet, S. Framework for life cycle sustainability assessment of municipal solid waste management systems with an application to a case study in Thailand. Waste Manag. Res. 2012, 30, 708-719. [CrossRef] [PubMed]

15. Amer, M.; Daim, T.U. Selection of renewable energy technologies for a developing county: A case of Pakistan. Energy Sustain. Dev. 2011, 15, 420-435. [CrossRef]

16. Plakas, K.V.; Georgiadis, A.A.; Karabelas, A.J. Sustainability assessment of tertiary wastewater treatment technologies: A multi-criteria analysis. Water Sci. Technol. 2016, 73, 1532-1540. [CrossRef] [PubMed]

17. Liang, X.; van Dijk, M.P. Cost benefit analysis of centralized wastewater reuse systems. J. Benefit-Cost Anal. 2012, 3, 5. [CrossRef]

18. Asano, T. Urban Water Recycling. Water Sci. Technol. 2005, 51, 83-89. [PubMed]

19. Beijing Water Authority. Analysis of Wastewater Reuse in Beijing; The Working Papers of Beijing Water Authority; Beijing Water Authority: Beijing, China, 2002.

20. Hernandez, F.; Urkiaga, A.; Fuentes, D.L.; Bis, B.; Chiru, E.; Balazs, B.; Wintgens, T. Feasibility Studies for Water Reuse Projects: An Economical Approach. Desalination 2006, 187, 253-261. [CrossRef]

21. Skeer, J.; Wang, Y. Carbon charges and natural gas use in china. Energy Policy 2005, 34, 2251-2262. [CrossRef]

22. Dahowski, R.T.; Li, X.; Davidson, C.L.; Wei, N.; Dooley, J.J.; Gentile, R.H. A preliminary cost curve assessment of carbon dioxide capture and storage potential in China. Energy Procedia 2009, 1, 2849-2856. [CrossRef]

23. Tol, R.S.J. The Marginal Damage Costs of Carbon Dioxide Emissions: An Assessment of the Uncertainties. Energy Policy 2005, 33, 2064-2074. [CrossRef]

24. Christova-Boal, D.; Eden, R.E.; McFarlane, S. An Investigation into Greywater Reuse for Urban Residential Properties. Desalination 1996, 106, 391-397. [CrossRef]

25. Ottoson, J.; Stenström, T.A. Faecal Contamination of Greywater and Associated Microbial Risks. Water Res. 2003, 37, 645-655. [CrossRef]

26. Haller, L.; Hutton, G.; Bartram, J. Estimating the Costs and Health Benefits of Water and Sanitation Improvements at Global Level. J. Water Health 2007, 5, 467-480. [CrossRef] [PubMed]

27. Aramaki, T.; Galal, M.; Hanaki, K. Estimation of reduced and increasing health risks by installation of urban wastewater systems. Water Sci. Technol. 2006, 53, 247-252. [CrossRef] [PubMed]

28. World Health Organization. Global Burden of Disease Report. 2004. Available online: www.who.org (accessed on 25 October 2016).

29. World Bank. Cost of Pollution in China: Economic Estimates of Physical Damages. 2007. Available online: www.worldbank.org/eapenvironment (accessed on 25 October 2016).

30. Camagni, R.; Gibelli, M.C.; Rigamonti, P. Urban Mobility and Urban Form: The Social and Environmental Costs of Different Patterns of Urban Expansion. Ecol. Econ. 2002, 40, 199-216. [CrossRef]

31. Luo, Y. The Social Cost of Residential Resettlement in China. Master's Thesis, Sichuan University, Chengdu, China, 2007. (In Chinese)

32. Beijing Municipal Statistics Bureau. Beijing Statistical Yearbook; Beijing Statistics Press: Beijing, China, 2014.

33. Wang, B. Wastewater Reclamation and Reuse in Chinese Cities. Available online: www.chinacitywater.org (accessed on 9 June 2009). (In Chinese) 
34. Beijing Water Authority. Pricing the Reused Water in Beijing; The Working Papers of Beijing Water Authority; Beijing Water Authority: Beijing, China, 2002.

35. Liu, X.; Zou, C. Calculating and forecasting shadow prices of all kinds of water in China and its nine major river basins. Adv. Sci. Technol. Water Resour. 2014, 34, 11-15. (In Chinese)

36. Wang, D.X.; Wang, H.; Yin, M.W. Water resource, water resource value, water resource shadow price. Water Resour. Evol. 1999, 10, 195-200. (In Chinese)

37. Yuan, R.H.; Zhu, J.L.; Tao, X.Y.; Mao, C.M. Application of shadow price method in calculation of water resources theoretical value. J. Nat. Resour. 2002, 17, 757-761. (In Chinese)

38. Li, H. A study on the relation between economic growth and employment elasticity. J. Financ. Econ. 2003, 29, 24-27. (In Chinese)

39. Ding, S.; Lu, X.; Jiang, J. Re-estimation of China's employment elasticity. J. Sichuan Univ. (Soc. Sci. Ed.) 2009, 2, 81-88.

40. Liu, F.X. The study on the monetary cost of noise pollution in Dalian city. Liaoning Urban Environ. Technol. 1999, 19, 27-29. (In Chinese)

41. Department of Planning and Program. The Water Planning in Beijing; Chinese Department of Planning and Program: Beijing, China, 2001.

(C) 2016 by the authors; licensee MDPI, Basel, Switzerland. This article is an open access article distributed under the terms and conditions of the Creative Commons Attribution (CC-BY) license (http://creativecommons.org/licenses/by/4.0/). 